\title{
Article
}

\section{Clinical risk factors that predict functional recovery in ischemic stroke patients with pre-stroke depression}

\author{
Leah Wormack, Brice Blum, Benjamin Bailes, Thomas I. Nathaniel * \\ University of South Carolina School of Medicine, SC 29605, USA \\ * Correspondence: nathanit@greenvillemed.sc.edu; Tel.: 8644559846; Fax: 8644558404
}

\begin{abstract}
Background. Specific clinical risk factors that may be associated with ambulatory outcome following thrombolysis therapy in ischemic stroke patients with pre-stroke depression is not fully understood. This was investigated. Methods. Multivariate analyses were performed to identify predictors of functional ambulatory outcomes. Patient demographics and clinical risk factors served as predictive variables, while improvement or no improvement in ambulatory outcome was considered as the primary outcome. Results. A total of 595 of these patients received rtPA of which 310 patients presented with pre-stroke depression, 217 had no improvement in functional outcome, while 93 patients presented with an improvement in functional outcome. Carotid artery stenosis $(\mathrm{OR}=11.577,95 \% \mathrm{CI}, 1.281-104.636, \mathrm{P}=0.029)$ and peripheral vascular disease $(\mathrm{OR}=18.040,95 \% \mathrm{CI}$, 2.956-110.086, $\mathrm{P}=0.002)$ were more likely to be associated with an improvement in ambulation. Antihypertensive medications ( $\mathrm{OR}=7.810,95 \% \mathrm{CI}, 1.401-43.529, \mathrm{P}=0.019)$, previous TIA (OR=0.444, $95 \% \mathrm{CI}, 0.517-0.971, \mathrm{P}=0.012)$, and congestive heart failure ( $\mathrm{OR}=0.217,95 \% \mathrm{CI}, 0.318-0.402, \mathrm{P}=0.030)$ were associated with a no improvement in ambulation. Conclusion. After adjustment for covariates, more clinical risk factors were associated with no improvement when compared with improvement in functional outcome following thrombolysis therapy in an acute ischemic stroke population with pre-stroke depression.
\end{abstract}

Keywords. Ambulation; Ischemic stroke; pre-stroke depression; recombinant tissue plasminogen activator (rtPA)

\section{Introduction}

Clinical outcomes following ischemic stroke in patients with depression manifest in various forms, including ambulation, which is relevant in the assessment of treatment outcomes [1]. Ambulatory behavior is known to be modulated by emotions and has long been recognized as an integral sign of depression [2], and can predict the course of the disease [3,4]. Alterations in the ambulatory status are well-known as clinically observable phenomena of depressed patients [5]. These alterations may be linked to abnormalities in the motor pathways that may also lead to alterations of ambulatory patterns in depressed patients [6]. Several studies [7-10] provide evidence that an improvement or lack of improvement in the ambulatory status of patients with depression is relevant for evaluation of course and treatment response [3,4,11]. After stroke, more than $60 \%$ of survivors present with a reduced ambulatory status [12,13]. It is known that in ischemic stroke patients, pre-stroke clinical risk factors may predict ambulatory recovery following thrombolysis therapy $[14,15]$.

While post-stroke depression is a common occurrence and linked with poor outcome [16-19], the effect of pre-stroke depression on treatment outcome in ischemic stroke patients is not well understood. Pre-stroke depression may be associated with abnormal modification of risk factors in ischemic stroke [20,21], and may affect functional ambulatory outcome following rtPA. However, clinical risk factors that may predict ambulatory outcome of ischemic stroke patients with pre-stroke depression are yet to be fully understood. We developed a logistic regression model to predict the 
recovery of ambulatory functions 14 days after stroke recovery. We tested the hypothesis that specific clinical risk factors may be predictive of ambulatory outcome in ischemic stroke patients with prestroke depression treated with thrombolysis therapy. There is a likelihood that the population of ischemic stroke patients with pre-stroke depression with improvement in functional ambulation after treatment with thrombolysis therapy maybe different from those with no improvement. In this context, there is a possibility that different clinical risk factors would be associated with improvement, when compared with no improvement in ambulatory function after rtPA in ischemic stroke patient with pre-stroke depression. The aim of this study is to identify clinical risk factors associated with ambulatory recovery in ischemic stroke patients with pre-stroke depression treated with thrombolysis therapy 14 days after recovery. Thrombolysis therapy is an FDA-approved treatment for acute ischemic stroke, and there is no clinical reason to withhold the use of rtPA based on pre-stroke depression alone. Therefore, understanding clinical risk factors that may affect ambulatory recovery in ischemic stroke patients with pre-stroke depression may help in the development of management strategies to improve the use of rtPA in ischemic stroke patients with pre-stroke depression.

\section{Materials and Methods}

\subsection{Research Design}

This study contains retrospective data obtained from a large stroke registry and was approved by the institutional Ethics Committee (approval number Pro00046787). Data within the Greenville Health System (GHS) stroke registry has been standardized according to the "Get with The Guidelines" (GWTG) stroke registry formed by the American Heart Association (AHA). Details in the ascertainment and data collection have previously been described [22-24]. Briefly, data was collected from 1466 ischemic stroke patients admitted to the stroke Unit of GHS between January 2014 and June 2016 with a diagnosis of acute ischemic stroke. Eligibility for rtPA was based on the AHA inclusion guidelines for early management of patients with acute ischemic stroke [25]. All cases of prospective clinical identification of acute ischemic stroke were confirmed by computed tomography (CT). Our data analysis utilized retrospective data of confirmed cases of acute ischemic stroke from the standardized registry. In this study, patients were included if they were, 1) discharged from the stroke unit of GHS between January 2014 and June 2016 with acute ischemic as their primary cause for hospitalization, 2) entered into the GWTG-Stroke registry and, 3) with documented history pre-stroke depression on admission.

We excluded patients if there was no documentation of medical history on admission, as well as patients with mild or improving stroke symptoms. Data on symptomatic hemorrhage was not included in our data collection. Our inclusion criteria allowed us to focus our analysis on ischemic stroke patients with a history of pre-stroke depression. We collected data on patient demographics, including age, sex, race (African-American/black, white or other) and Hispanic ethnicity. Information about medical history was obtained from electronic medical records, and we collected and analyzed data on clinical risk factors for stroke in patients with pre-stroke depression. Clinical risk factors include atrial fibrillation, coronary artery disease or prior myocardial infarction, carotid stenosis, drug abuse, diabetes mellitus, dyslipidemia, congestive heart failure, obesity, hypertension, peripheral vascular disease, previous stroke, transient ischemic attack (TIA), renal insufficiency, or smoking. While data from history of pre-stroke depression was abstracted from the medical record, data collected for antidepressant medication was not directly linked to pre-stroke depression for each patient. Data for use of antihypertensive medication, cholesterol reducing agents, and antihypertensive agents also collected. Medical records on hospital course, initial NIHSS score and examination findings including weakness, aphasia, systolic and diastolic blood pressures, and status at discharge were collected. Clinical parameters relating to the hospital course included data of stroke patients in the use of rtPA for the 4.5 hours of the protocol. We included data on laboratory analyses of samples including serum lipid panel, LDL, total cholesterol and creatinine levels. Ambulatory status was characterized using a three-level tiered system at both admission and at discharge, 
assigning each patient to one of the following: 1) unable to ambulate, 2) able to ambulate with assistance, 3) able to ambulate independently. This allowed us to analyze changes in ambulation status from admission to discharge in patients who received rtPA, as well as identify risk factors associated with improvement or no improvement in ambulatory status.

\section{Statistical analysis}

We analyzed our data using the SPSS Statistics Software version 15.0 (Chicago, IL). We utilized descriptive statistics to characterize the demographic and clinical risk factors in ischemic stroke patients with pre-stroke depression treated with rtPA and characterize them based on improvement or no improvement in ambulatory status. We tested the normality of our data using the KolmogorovSmirnov test. All continuous variables were analyzed using a Student-t-test, while discrete variables were analyzed using Pearson's Chi-Squared analyses. The mean, standard deviation, and range were determined for all continuous variables and significant differences at $\mathrm{P}<0.05$ were determined. The number of patients and percentage of patients in each category were analyzed for all discrete variables.

We used logistic regression analysis to identify predictive clinical risk factors in a population of ischemic stroke patients with pre-stroke depression who were treated with rtPA. This sample population was then divided into two groups: improvement ambulatory status after treatment and no improvement in ambulatory status after treatment. In our logistic regression analysis, we retained parameters that the p-value were less than 0.05 , and parameters with $p$-values $>0.05$ were excluded and eliminated stepwise. We then re-considered and added parameters that were initially eliminated in the model if they met the criteria of $\mathrm{p}<0.05$. We adjusted for clinical covariates that were significant in the unadjusted univariate analysis using the backward elimination method with conventional $\mathrm{P}$ value $<0.05$.

The primary outcome of our logistic model was the identification of baseline clinical risk factors that were significantly associated with improvement or no improvement in ambulation following thrombolysis therapy in ischemic stroke patients with pre-stroke depression. This approach allowed us to identify specific clinical risk factors associated with an improvement or no improvement in ambulation recovery in the multivariate analysis. We used the variance inflation factor to determine independence of variables included in the regression model to address the issue of collinearity or interactions between independent variables. We tested the validity of our model using a HosmerLemeshow test, and the overall correct classification percentage and the area under the Receiver Operating Curve (ROC) for score prediction was determined. This allowed us to test the sensitivity, specificity and accuracy of our logistic model. Odds ratios (ORs) were determined from the logistic regression and significance was set at the probability level of 0.05 . We then use the odds ratio values to predict the odds of attaining a specific ambulation outcome in ischemic stroke patients with prestroke depression treated with thrombolysis therapy.

\section{Results}

A total of 4,665 ischemic stroke patients were identified. Of this population, 1,446 patients were eligible for rtPA and 595 of these patients received rtPA. Of the 595 patients treated with thrombolysis therapy, 310 patients presented with a documented history of pre-stroke depression. Of the acute ischemic stroke patients with pre-stroke depression who received rtPA, 217 patients presented with no improvement, and there was an improvement in ambulation for 93 patients (Table 1).Compared to the no improvement group, the improvement rtPA population was younger $(64.18 \pm 15.2 \mathrm{vs}$. 67.17 $\pm 14.5)$, included more males $(66.7 \%$ vs $61.3 \%$ ), and fewer females $(33.3 \%$ vs $38.7 \%)$. Those with an improvement in ambulation were more likely to present with lower rates of atrial fibrillation or atrial flutter (15.1\% vs $19.8 \%$ ), less likely to have dyslipidemia (60.2\% vs. $64.1 \%)$, family history of stroke (9.7\% vs $13.4 \%)$, congestive heart failure (9.7\% vs. $17.5 \%)$, hypertension( $82.8 \%$ vs $85.3 \%)$, prior TIA (9.7\% vs $14.7 \%)$, chronic renal disease (9.7\% vs $15.7 \%)$, diabetes $(40.9 \%$ vs $44.2 \%)$, and are less likely to receive treatment in a telestroke setting $(8.6 \%$ vs $10.1 \%)$. 
Table 1. Demographic and clinical characteristics of ischemic stroke patients with pre-stroke depression. Results for continuous variables are presented as Mean \pm S.D, while discrete data are presented percentage frequency. Pearson's Chi-Squared is used compare differences between improvement and no improvement in ambulatory outcome in rPA treated groups.

\begin{tabular}{|c|c|c|c|}
\hline & Not Improved (217) & Improved (93) & Significance \\
\hline \multicolumn{3}{|l|}{ Age Group } & 0.432 \\
\hline$<50$ years & $26(12.0)$ & $18(19.4)$ & \\
\hline $50-59$ & $39(18.0)$ & $16(17.2)$ & \\
\hline $60-69$ & $49(22.6)$ & $23(24.7)$ & \\
\hline 70-79 & $54(24.9)$ & $18(19.4)$ & \\
\hline$>80$ years & $49(22.6)$ & $18(19.4)$ & \\
\hline Mean \pm SD & $67.17 \pm 14.5$ & $64.18 \pm 15.2$ & 0.110 \\
\hline \multicolumn{3}{|l|}{ Race } & 0.200 \\
\hline Caucasion & $186(85.7)$ & $79(85.5)$ & \\
\hline African-American & $25(11.5)$ & $14(15.1)$ & \\
\hline Other & $6(2.8)$ & $0(0.0)$ & \\
\hline \multicolumn{3}{|l|}{ Gender } & 0.369 \\
\hline Male & $133(61.3)$ & $62(66.7)$ & \\
\hline \multirow{2}{*}{\multicolumn{4}{|c|}{ Medical History }} \\
\hline & & & \\
\hline Atrial Fibrillation & $43(19.8)$ & $14(15.1)$ & 0.321 \\
\hline CAD & $90(41.5)$ & $30(32.3)$ & 0.127 \\
\hline Carotid Stenosis & $15(6.9)$ & $7(7.5)$ & 0.847 \\
\hline Diabetes & $96(44.2)$ & $38(40.9)$ & 0.582 \\
\hline Drug Abuse & $16(7.4)$ & $11(11.8)$ & 0.202 \\
\hline Dyslipidemia & $139(64.1)$ & $56(60.2)$ & 0.521 \\
\hline Family stroke history & $29(13.4)$ & $9(9.7)$ & 0.364 \\
\hline Congestive heart filure & $38(17.5)$ & $9(9.7)$ & 0.078 \\
\hline Hypertension & $185(85.3)$ & $77(82.8)$ & 0.584 \\
\hline Obesity & $153(70.5)$ & $68(73.1)$ & 0.641 \\
\hline Prior Stroke & $74(34.1)$ & $33(35.5)$ & 0.815 \\
\hline Prior TIA & $32(14.7)$ & $9(9.7)$ & 0.227 \\
\hline Peripheral vascular disease & $20(9.2)$ & $11(11.8)$ & 0.482 \\
\hline Chronic renal disease & $34(15.7)$ & $9(9.7)$ & 0.162 \\
\hline Smoking History & $53(24.4)$ & $29(31.2)$ & 0.216 \\
\hline GHS Telestroke & $22(10.1)$ & $8(8.6)$ & 0.675 \\
\hline \multicolumn{4}{|l|}{ Medications } \\
\hline Antihypertensives & $170(78.3)$ & $70(75.3)$ & 0.553 \\
\hline Cholesterol reducing agents & $125(57.6)$ & $51(54.8)$ & 0.652 \\
\hline Antidiabetic agents & $80(36.9)$ & $29(31.2)$ & 0.337 \\
\hline Antidepressants & $170(78.3)$ & $80(86.0)$ & 0.117 \\
\hline tPA & $97(44.7)$ & $56(60.2)$ & $0.012^{*}$ \\
\hline \multicolumn{3}{|l|}{ NIH Stroke Scale } & $0.005^{*}$ \\
\hline $0-9$ & $138(67.0)$ & $40(44.4)$ & \\
\hline $10-14$ & $22(10.7)$ & $20(22.2)$ & \\
\hline $15-20$ & $19(9.2)$ & $15(16.7)$ & \\
\hline $21-25$ & $15(7.3)$ & $9(10.0)^{\prime}$ & \\
\hline $26-42$ & $12(5.8)$ & $6(6.7)$ & \\
\hline Mean \pm SD & $8.84 \pm 8.0$ & $12.29 \pm 7.6$ & $0.001^{*}$ \\
\hline \multicolumn{4}{|l|}{ BMI } \\
\hline Mean \pm SD & $29.56 \pm 7.1$ & $29.96 \pm 8.1$ & 0.691 \\
\hline \multicolumn{4}{|l|}{ Total Cholesterol } \\
\hline Mean \pm SD & $168.34 \pm 47.9$ & $170.27 \pm 51.8$ & 0.769 \\
\hline \multicolumn{4}{|l|}{ LDL } \\
\hline $\begin{array}{l}\text { Mean } \pm \text { SD } \\
\text { Serum Creatinine }\end{array}$ & $100.77 \pm 38.6$ & $98.26 \pm 40.2$ & 0.751 \\
\hline Mean \pm SD & $1.47 \pm 2.3$ & $1.24 \pm 0.96$ & 0.387 \\
\hline Systolic Blood Pressure & $146.2 \pm 27$ & $150.2 \pm 19$ & 0.315 \\
\hline Diastolic Blood pressure & $80.3 \pm 23$ & $84.1 \pm 17$ & 0.293 \\
\hline
\end{tabular}

In addition, the improvement in ambulation group demonstrated higher rates of carotid artery stenosis $(7.5 \%$ vs $6.9 \%)$, prior stroke( $35.5 \%$ vs $34.1 \%)$, history of drug abuse $(11.8 \%$ vs $7.4 \%)$, obesity $(73.1 \%$ vs $70.5 \%)$, peripheral vascular disease $(11.8 \%$ vs $9.2 \%)$, and smoking history $(31.2 \%$ vs $24.4 \%$ ). Patients with improvement in ambulation were less likely to take antihypertensive medication ( $75.3 \%$ vs $78.3 \%$ ), and cholesterol reducing agents ( $54.8 \%$ vs $57.6 \%)$. Compared with the no improvement group, those with an improvement in ambulation were more likely to take antidepressants $(86.0 \%$ vs $78.3 \%)$, present with higher NIHSS scores (12.29 \pm 7.6 vs $8.84 \pm 8.0)$, high serum cholesteroal $(170.27 \pm 51.8 \mathrm{mg} / \mathrm{dl}$ vs $168.34 \pm 47.9 \mathrm{mg} / \mathrm{dl})$, and BMI ( $29.96 \pm 8.1 \mathrm{vs} 29.56 \pm 7.1)$, lower low density lipoprotein (LDL) $(98.26 \pm 8.1$ vs $100.77 \pm 38.6 \mathrm{mg} / \mathrm{dl})$, serum creatine $(1.24 \pm 0.96$ vs $1.47 \pm 2.3 \mathrm{mg} / \mathrm{dl})$, high systolic blood pressure $(150.2 \pm 19.0 \mathrm{vs} 146.2 \pm 27.0 \mathrm{~mm} \mathrm{Hg})$ and diastolic blood 
pressure values $(84.1 \pm 17.0$ vs $80.3 \pm 23 \mathrm{~mm} \mathrm{Hg})$. Apart from use of rtPA, and NIH scale scores, all other clinical variables including age, race, gender, atrial fibrillation or atrial flutter, carotid artery disease, dyslipidemia, congestive heart, hypertension, prior stroke, prior, and chronic renal disease were not significantly different between the improvement and the no improvement in ambulation group.

Following adjustment for the cofounding effects of non-significant variables in the total population (Table 2), only NIHSS score $(\mathrm{OR}=1.275,95 \% \mathrm{CI}, 1.006-1.616, \mathrm{P}=0.045$ ) was associated with an improvement in ambulatory outcome. The area under the curve (AUROC $=0.707,95 \% \mathrm{CI}$, 0.639-0.776, $\mathrm{P}<0.001$ ) of accurate classification, indicates a good fit for the regression model. For the improvement in ambulation group (Table 3), carotid artery stenosis (OR=11.577, 95\% CI, 1.281 104.636, $\mathrm{P}=0.029)$ and peripheral vascular disease $(\mathrm{OR}=18.040,95 \% \mathrm{CI}, 2.956-110.086, \mathrm{P}=0.002)$ were more likely to be associated with an improved ambulatory outcome, while antihypertensive medication $(\mathrm{OR}=0.192,95 \% \mathrm{CI}, 0.035-1.067, \mathrm{P}=0.051)$ was predicted to be associated with no improvement in ambulation following thrombolysis therapy. The discriminatory capability of the model was strong with area under the curve (AUROC $=0.827,95 \% \mathrm{CI}, 0759-0.895, \mathrm{P}<0.001$ ).

For the no improvement group, NIH scale score (OR=0.887, 95\% CI, $0.830-0.948, \mathrm{P}<0.001)$, antihypertensive medications $(\mathrm{OR}=7.810,95 \% \mathrm{CI}, 1.401-43.529, \mathrm{P}=0.019)$, previous TIA (OR=0.444, 95\% CI, $0.517-0.971, \mathrm{P}=0.012)$, and congestive heart failure $(\mathrm{OR}=0.217,95 \% \mathrm{CI}, 0.318-0.402, \mathrm{P}=0.030)$ were significantly associated with no improvement in ambulation (Table 4). The discriminating ability of the model was strong as shown by the ROC curve, with area under the curve (AUROC= 0.842, 95\% CI, 0778-0.906, $\mathrm{P}<0.001)$.

Table 2. Results for the logistic regression model that predicts clinical risk factors associated with improvement or no improvement in ambulatory recovery for an ischemic stroke population with prestroke depression.

\begin{tabular}{|c|c|c|c|c|c|c|}
\hline \multirow[b]{3}{*}{ Age } & \multirow[b]{2}{*}{ B } & & \multicolumn{4}{|c|}{ 95\% C.I.for Odds Ratio } \\
\hline & & Wald & Sig. & Odds Ratio L & & \\
\hline & -0.015 & 1.458 & 0.227 & 0.985 & 0.961 & 1.009 \\
\hline Gender & -0.056 & 0.029 & 0.864 & 0.945 & 0.495 & 1.803 \\
\hline Afib & -0.048 & 0.011 & 0.915 & 0.954 & 0.400 & 2.275 \\
\hline CAD & -0.360 & 1.194 & 0.275 & 0.697 & 0.365 & 1.331 \\
\hline Carotid Stenosis & 0.587 & 0.970 & 0.325 & 1.798 & 0.559 & 5.780 \\
\hline Diabetes & 0.886 & 3.042 & 0.081 & 2.425 & 0.896 & 6.564 \\
\hline Drug Abuse & 0.597 & 0.995 & 0.319 & 1.817 & 0.562 & 5.880 \\
\hline $\begin{array}{l}\text { DysLip } \\
\text { Family history of stroke } \\
\text { Heart Failure }\end{array}$ & $\begin{array}{r}-0.193 \\
-0.707 \\
-0.739\end{array}$ & $\begin{array}{l}0.248 \\
2.132 \\
2.299\end{array}$ & $\begin{array}{l}0.619 \\
0.144 \\
0.129\end{array}$ & $\begin{array}{l}0.825 \\
0.493 \\
0.478\end{array}$ & $\begin{array}{l}0.386 \\
0.191 \\
0.184\end{array}$ & $\begin{array}{l}1.761 \\
1.274 \\
1.241\end{array}$ \\
\hline Hypertension & 0.451 & 0.727 & 0.394 & 1.570 & 0.557 & 4.429 \\
\hline Obesity & 0.074 & 0.028 & 0.867 & 1.077 & 0.453 & 2.558 \\
\hline Previous Stroke & 0.172 & 0.254 & 0.614 & 1.187 & 0.609 & 2.316 \\
\hline Previous TIA & -0.811 & 3.007 & 0.083 & 0.444 & 0.178 & 1.112 \\
\hline Peripheral vascular disease & 0.756 & 2.422 & 0.120 & 2.131 & 0.822 & 5.523 \\
\hline Chronic renal disease & -0.499 & 0.929 & 0.335 & 0.607 & 0.220 & 1.674 \\
\hline History of Smoking & 0.081 & 0.048 & 0.827 & 1.084 & 0.524 & 2.242 \\
\hline Race & -0.352 & 0.694 & 0.405 & 0.704 & 0.308 & 1.609 \\
\hline $\begin{array}{l}\text { NIHSS } \\
\text { Treatment with rTPA }\end{array}$ & $\begin{array}{l}0.243 \\
0.570\end{array}$ & $\begin{array}{l}4.024 \\
3268\end{array}$ & $\begin{array}{r}0.045^{*} \\
0.071\end{array}$ & $\begin{array}{l}1.275 \\
1.68\end{array}$ & $\begin{array}{l}1.006 \\
0.953\end{array}$ & $\begin{array}{l}1.616 \\
3.278\end{array}$ \\
\hline $\begin{array}{l}\text { Anthypertensive Medication } \\
\text { Chlosterol Reducing Agent }\end{array}$ & $\begin{array}{r}-0.472 \\
0.203\end{array}$ & $\begin{array}{l}0.994 \\
0.265\end{array}$ & $\begin{array}{l}0.319 \\
0.607\end{array}$ & $\begin{array}{l}0.624 \\
1.225\end{array}$ & $\begin{array}{l}0.247 \\
0.565\end{array}$ & $\begin{array}{l}1.577 \\
2.657\end{array}$ \\
\hline Antidiabetic Agent & -0.849 & 2.333 & 0.127 & 0.428 & 0.144 & 1.272 \\
\hline Antidepressant Agent & 0.457 & 1.165 & 0.280 & 1.579 & 0.689 & 3.616 \\
\hline Totalcholesterol & 0.000 & 0.001 & 0.974 & 1.000 & 0.982 & 1.018 \\
\hline LDL & 0.001 & 0.015 & 0.902 & 1.001 & 0.979 & 1.024 \\
\hline Serum creatinine & -0.109 & 0.329 & 0.566 & 0.897 & 0.618 & 1.301 \\
\hline Systolic Blood Pressure & 0.002 & 0.056 & 0.813 & 1.002 & 0.988 & 1.015 \\
\hline Diastolic Blood Pressure & 0.005 & 0.309 & 0.578 & 1.005 & 0.988 & 1.022 \\
\hline BMI & 0.012 & 0.177 & 0.674 & 1.013 & 0.956 & 1.073 \\
\hline
\end{tabular}

Adjusted $\mathrm{OR}<1$ indicates clinical and demographic factors associated with no improvement in ambulation while Adjusted $\mathrm{OR}>1$ reveal factor associated an improvement in ambulation following thrombolysis therapy. Hosmer-Lemeshow test, Cox \& Snell $\left(R^{2}=0.0 .707\right)$, and the overall classified percentage of $70.7 \%$ was applied to check the model fitness. ${ }^{*}$ Indicates statistical significance $(\mathrm{P}<0.05)$ with $95 \%$ a confidence interval. 
Table 3. Predictive clinical and demographic variables associated with an improvement in ambulation for ischemic stroke population with pre-stroke depression, treated with rtPA.

\begin{tabular}{|c|c|c|c|c|c|c|}
\hline & & & & & \multicolumn{2}{|c|}{$\begin{array}{l}95 \% \text { C.I.for Odds } \\
\text { Ratio }\end{array}$} \\
\hline & B & Wald & Siq. & $\begin{array}{l}\text { Odds } \\
\text { Ratio }\end{array}$ & Lower & Upper \\
\hline Age & -0.007 & 0.117 & 0.732 & 0.993 & 0.957 & 1.032 \\
\hline Gender & -0.015 & 0.001 & 0.980 & 0.985 & 0.310 & 3.130 \\
\hline Afib & -1.071 & 1.153 & 0.283 & 0.343 & 0.048 & 2.421 \\
\hline CAD & -0.855 & 2.419 & 0.120 & 0.425 & 0.145 & 1.249 \\
\hline Carotid Stenosis & 2.449 & 4.754 & $0.029^{*}$ & 11.577 & 1.281 & 104.636 \\
\hline Diabetes & 0.878 & 0.793 & 0.373 & 2.407 & 0.348 & 16.636 \\
\hline Drug Abuse & 1.806 & 3.914 & 0.048 & 6.086 & 1.017 & 36.424 \\
\hline DysLip & -0.869 & 1.923 & 0.166 & 0.420 & 0.123 & 1.432 \\
\hline Family history of stroke & -1.371 & 2.721 & 0.099 & 0.254 & 0.050 & 1.294 \\
\hline Heart Failure & -1.832 & 4.650 & 0.031 & 0.160 & 0.030 & 0.846 \\
\hline Hypertension & 1.425 & 2.046 & 0.153 & 4.157 & 0.590 & 29.295 \\
\hline Obesity & 0.900 & 1.711 & 0.191 & 2.460 & 0.639 & 9.474 \\
\hline Previous Stroke & 0.158 & 0.070 & 0.792 & 1.172 & 0.361 & 3.798 \\
\hline Previous TIA & -1.734 & 4.914 & 0.027 & 0.177 & 0.038 & 0.818 \\
\hline Peripheral vascular disease & 2.893 & 9.825 & $0.002^{*}$ & 18.040 & 2.956 & 110.086 \\
\hline Chronic renal disease & -1.394 & 1.650 & 0.199 & 0.248 & 0.030 & 2.081 \\
\hline History of Smoking & 0.389 & 0.432 & 0.511 & 1.476 & 0.462 & 4.716 \\
\hline Race & -0.009 & 0.000 & 0.987 & 0.991 & 0.314 & 3.125 \\
\hline NIHSS & 0.438 & 3.976 & 0.046 & 1.549 & 1.008 & 2.383 \\
\hline Anthypertensive Medication & -1.648 & 3.557 & $0.051^{*}$ & 0.192 & 0.035 & 1.067 \\
\hline Chlosterol Reducing Agent & 0.269 & 0.197 & 0.657 & 1.308 & 0.400 & 4.282 \\
\hline Antidiabetic Agent & -0.127 & 0.015 & 0.902 & 0.881 & 0.117 & 6.632 \\
\hline Antidepressant Agent & 0.478 & 0.407 & 0.524 & 1.613 & 0.371 & 7.011 \\
\hline Totalcholesterol & 0.008 & 0.293 & 0.588 & 1.008 & 0.980 & 1.035 \\
\hline LDL & -0.009 & 0.291 & 0.590 & 0.991 & 0.958 & 1.025 \\
\hline Serum creatinine & -0.070 & 0.058 & 0.810 & 0.933 & 0.529 & 1.644 \\
\hline Systolic Blood Pressure & -0.003 & 0.111 & 0.739 & 0.997 & 0.976 & 1.017 \\
\hline Diastolic Blood Pressure & -0.004 & 0.093 & 0.760 & 0.996 & 0.967 & 1.025 \\
\hline BMI & -0.011 & 0.061 & 0.805 & 0.989 & 0.904 & 1.082 \\
\hline
\end{tabular}

Adjusted $\mathrm{OR}<1$ denote factors that are associated with no improvement in ambulation while adjusted OR $>1$ denote factors that are associated with an improvement in ambulation. Hosmer-Lemeshow test, Cox \& Snell $\left(\mathrm{R}^{2}=0.827\right)$. The overall classified percentage of $82.7 \%$ was applied to check for the fitness of the logistic regression model. * Indicates statistical significance $(\mathrm{P}<0.05)$ with $95 \%$ a confidence interval. 
Table 4. Clinical factors that were associated with no improvement in ambulation for ischemic stroke population with pre-stroke depression treated with rtPA.

\begin{tabular}{|c|c|c|c|c|c|c|}
\hline \multirow[b]{3}{*}{ Age } & \multirow[b]{2}{*}{ B } & \multirow[b]{2}{*}{ Wald } & \multirow[b]{2}{*}{ Sig. } & \multirow[b]{2}{*}{$\begin{array}{l}\text { Odds } \\
\text { Ratio }\end{array}$} & \multicolumn{2}{|c|}{$\begin{array}{l}95 \% \text { C.I.for Odds } \\
\text { Ratio }\end{array}$} \\
\hline & & & & & Lower & Upper \\
\hline & 0.006 & 0.095 & 0.757 & 1.006 & 0.970 & 1.043 \\
\hline Gender & 0.159 & 0.089 & 0.766 & 1.173 & 0.411 & 3.350 \\
\hline Afib & 0.970 & 1.336 & 0.248 & 2.637 & 0.509 & 13.646 \\
\hline CAD & 0.529 & 1.080 & 0.299 & 1.697 & 0.626 & 4.598 \\
\hline Carotid Stenosis & -2.549 & 5.874 & 0.015 & 0.078 & 0.010 & 0.614 \\
\hline Diabetes & -0.334 & 0.138 & 0.710 & 0.716 & 0.123 & 4.169 \\
\hline Drug Abuse & -1.066 & 1.597 & 0.206 & 0.344 & 0.066 & 1.799 \\
\hline DysLip & 0.675 & 1.272 & 0.259 & 1.963 & 0.608 & 6.342 \\
\hline Family history of stroke & 1.118 & 2.100 & 0.147 & 3.059 & 0.674 & 13.874 \\
\hline Heart Failure & 2.503 & 0.709 & $0.030^{*}$ & 0.217 & 0.318 & 0.402 \\
\hline Hypertension & -1.663 & 2.789 & 0.095 & 0.190 & 0.027 & 1.335 \\
\hline Obesity & -0.530 & 0.746 & 0.388 & 0.589 & 0.177 & 1.958 \\
\hline Previous Stroke & -0.065 & 0.012 & 0.912 & 0.937 & 0.296 & 2.971 \\
\hline Previous TIA & 1.863 & 0.374 & $0.012^{*}$ & 0.444 & 0.517 & 0.971 \\
\hline Peripheral vascular disease & -2.052 & 6.683 & 0.081 & 0.128 & 0.027 & 0.609 \\
\hline Chronic renal disease & 1.128 & 1.276 & 0.259 & 3.090 & 0.437 & 21.866 \\
\hline History of Smoking & 0.184 & 0.108 & 0.743 & 1.203 & 0.400 & 3.620 \\
\hline Race & -0.104 & 0.037 & 0.848 & 0.901 & 0.309 & 2.625 \\
\hline NIHSS & -0.120 & 12.429 & $<0.001^{*}$ & 0.887 & 0.830 & 0.948 \\
\hline Antihypertensive Medication & 2.055 & 5.4990 & $00.019^{\star}$ & 0.810 & 0.401 & 0.529 \\
\hline Chlosterol Reducing Agent & -0.206 & 0.131 & 0.717 & 0.814 & 0.267 & 2.481 \\
\hline Antidiabetic Agent & -0.379 & 0.161 & 0.688 & 0.685 & 0.108 & 4.357 \\
\hline Antidepressant Agent & -0.815 & 1.333 & 0.248 & 0.443 & 0.111 & 1.766 \\
\hline Totalcholesterol & -0.010 & 0.576 & 0.448 & 0.991 & 0.966 & 1.015 \\
\hline LDL & 0.013 & 0.658 & 0.417 & 1.013 & 0.982 & 1.044 \\
\hline Serum creatinine & 0.100 & 0.128 & 0.720 & 1.105 & 0.639 & 1.911 \\
\hline $\begin{array}{l}\text { Systolic Blood Pressure } \\
\text { Diastolic Blood Pressure }\end{array}$ & $\begin{array}{r}0.007 \\
-0.006\end{array}$ & $\begin{array}{l}0.556 \\
0.235\end{array}$ & $\begin{array}{l}0.456 \\
0.628\end{array}$ & $\begin{array}{l}1.007 \\
0.994\end{array}$ & $\begin{array}{l}0.989 \\
0.968\end{array}$ & $\begin{array}{l}1.026 \\
1.020\end{array}$ \\
\hline BMI & 0.012 & 0.080 & 0.778 & 1.012 & 0.930 & 1.102 \\
\hline
\end{tabular}

Adjusted $\mathrm{OR}<1$ indicates factors associated with no improvement while adjusted $\mathrm{OR}>1$ indicates factors associated with an improvement. Hosmer-Lemeshow test, Cox \& Snell $\left(R^{2}=0.842\right)$, and the overall classified percentage of $84.2 \%$ was applied to check for the fitness of the logistic regression model. * Indicates statistical significance $(\mathrm{P}<0.05)$ with $95 \%$ a confidence interval.

\section{Discussion}

The goal of this study was to investigate clinical risk factors that may be associated with an improvement or no improvement in the recovery of ambulatory functions following thrombolysis therapy in acute ischemic stroke patients with pre-stroke depression. In the univariate analysis, we found that the proportion of ischemic stroke patients with pre-stroke depression who presented with no improvement in ambulation after treatment with rtPA was higher than those with an improvement in ambulation. This may be linked to differences in the proportion of clinical factors between patients that presented with an improvement and those with no improvement in their ambulation status. We expected that the use of antidepressants would be identified as a variable associated with ambulatory status. However, the univariate analysis as well as the adjusted analysis did not reveal a significant association of antidepressants with ambulatory outcome in ischemic stroke patients with pre-stroke depression treated with thrombolysis therapy. It is possible that the variation in the effects or use of antidepressants may be associated with stroke severity, rather than with the ambulation status.

In the univariate analysis, NIHSS (indicator of stroke severity) was associated with a significant improvement in ambulation among ischemic stroke patients with pre-stroke depression. This effect 
was sustained in the adjusted analysis for the total population of ischemic stroke patients with prestroke depression and was associated with no improvement in the group with no improvement in ambulation following rtPA. In general, the initial NIHSS score is a strong predictor of stroke severity and may predict functional outcome as well. In the univariate analysis, stroke severity, demonstrated by NIHSS, was between 0 and 14 for many of the patients with no improvement following treatment with rtPA. The adjusted analysis associated initial NIHSS with both an improvement and no improvement in ambulation following rtPA. This finding indicates that the severity of stroke is not enough to predict functional ambulatory outcomes, and that clinical risk factors may as well play a significant role [26, 27].

In the population that presented with an improvement in ambulation, we observed that in the adjusted analysis, patients that presented with carotid artery stenosis and peripheral vascular disease were more likely to be associated with an improvement in ambulation. However, patients that took antihypertensive medications were more likely to be associated with no improvement following thrombolysis therapy. Because clinical risk factors associated with an improvement in functional ambulatory recovery maybe be different between the population with an improvement and those with no improvement, we performed additional analyses to evaluate if these factors may significantly differ. Our findings indicate that in the no improvement group, the effect of carotid artery disease and peripheral vascular disease, which were significant in the improvement group, were attenuated in the no improvement group. Moreover, our adjusted analysis revealed that previous TIA, congestive heart disease, and use of antihypertensive medications were more likely to be significantly associated with no improvement in functional ambulatory recovery in ischemic stroke patients with pre-stroke depression.

Previous TIA is not a formal contraindication for rtPA, especially if the TIA was at least three months before the onset of stroke [28] [22, 29]. However, it has been shown that the onset of TIA within 24 hours of stroke may lead to a poor outcome following rtPA [30, 31]. It is possible that some ischemic stroke patients with pre-stroke depression may present an invisible TIA in the CT scans making it difficult to detect and this may affect treatment outcome with rtPA. This might be the case in ischemic stroke patients with pre-stroke depression that received rtPA resulting in no improvement outcome in functional ambulatory recovery. The association between antihypertensive medication and depression is well documented in the literature [32, 33]. It is known that if depression occurs prior to stroke, medication use plays a role in the treatment outcome of the stroke [21,34]. It is also known that clinical risk factors contribute to, or worsen, the underlying disease such as depression and stroke [28]. However, the relationship between certain clinical risk factors, such as congestive heart failure, with treatment response to rtPA and functional ambulatory outcome in ischemic stroke patients with pre-stroke depression is not known.

Depression is an independent risk factor for the onset of congestive heart failure [35, 36], and subclinical depressive symptoms are also correlated with an increased risk of stroke [37]. The biological variables that trigger this relationship are due to multiple alterations in neuroimmunoendocrine proteins in depressed patients, especially in the acute phase [38]. It is not clear how these factors interact with rtPA to affect functional ambulatory recovery in ischemic stroke patients with pre-stroke depression, and this is beyond the scope of the current study. However, ample evidence indicates that congestive heart failure may have a causal relationship with depression in stroke patients [39-42]. This is especially important since certain areas in the brain, including the medial temporal region, an area associated with the pathophysiology of depression, are particularly vulnerable to perfusion deficits which arise in the context of congestive heart failure [43, 44]. Clinically, our results indicate that congestive heart failure, antihypertensive medications, and previous TIA are important clinical risk factors that may affect the treatment outcomes of thrombolysis therapy and affect functional ambulatory recovery in ischemic stroke patients with prestroke depression. Our findings have practical implications and suggest the need for the development of an effective strategy to manage the combined effect of congestive heart failure, antihypertensive medications, and TIA in ischemic stroke patients with pre-stroke depression. 
Our study has limitations. The retrospective nature of our data may indicate the possibility of selection bias. In addition, the absence of pre-stroke functional status data including pre-stroke $\mathrm{mRS}$ and post treatment NIHSS scores did not allow for the comparison of ambulatory recovery and NIHSS scores or mRS to be evaluated. Depression is a common post-stroke complication and prestroke depression is known to contribute to treatment outcome following thrombolysis therapy. An important contribution of the current study to existing literature is identification of specific clinical risk factors that are significantly associated with functional ambulatory outcome in ischemic stroke patient with incidence of pre-stroke depression who received thrombolysis therapy.

\section{Conclusion}

In this study, we have shown that few acute ischemic stroke patients with pre-stroke depression received rtPA, and more clinical risk factors were associated with no improvement in functional outcome when compared with those that were associated an improvement in ambulation among ischemic stroke patients with a history of pre-stroke depression. Our findings reveal that congestive heart failure, antihypertensive medications, and previous TIA are significant clinical risk factors that may affect the treatment outcomes of thrombolysis therapy in ischemic stroke patients with a history of pre-stroke depression. Future studies should focus on effective strategies to manage these clinical risk factors to improve treatment outcomes of thrombolytic therapy in ischemic stroke patients with pre-stroke depression.

Acknowledgments. We thank the stroke unit of Greenville Health system for helping in the data collection.

Authors' contribution. LW, BB, BB and TIN designed the concept, experimental design and data analysis, while TIN critically revised the drafts read and approved the last version of this manuscript. All authors have provided the corresponding author with permission to be named in the manuscript and approved the submission of this manuscript.

Funding: This study was funded by the Fullerton Foundation.

\section{Conflicts of Interest: None}

\section{References}

1. D. Bennabi, P. Vandel, C. Papaxanthis, T. Pozzo, E. Haffen, Psychomotor Retardation in Depression: A Systematic Review of Diagnostic, Pathophysiologic, and Therapeutic Implications, Biomed Research International 4 (2013) 1-18.

2. G.A. Jacob, K. Zvonik, S. Kamphausen, A. Sebastian, S. Maier, A. Philipsen, L.T. van Elst, K. Lieb, O. Tuscher, Emotional modulation of motor response inhibition in women with borderline personality disorder: an fMRI study, Journal of Psychiatry \& Neuroscience 38(3) (2013) 164-172.

3. C. Sobin, H.A. Sackeim, Psychomotor symptoms of depression, American Journal of Psychiatry 154(1) (1997) 4-17.

4. S. Walther, J.A. Bernard, V.A. Mittal, S.A. Shankman, The utility of an RDoC motor domain to understand psychomotor symptoms in depression, Psychological Medicine 49(2) (2019) 212-216.

5. G.E. Miller, S. Cohen, T.B. Herbert, Pathways linking major depression and immunity in ambulatory female patients, Psychosomatic Medicine 61(6) (1999) 850-860.

6. T. Bracht, A. Federspiel, S. Schnell, H. Horn, O. Hofle, R. Wiest, T. Dierks, W. Strik, T.J. Muller, S. Walther, Cortico-Cortical White Matter Motor Pathway Microstructure Is Related to Psychomotor Retardation in Major Depressive Disorder, PloS one 7(12) (2012).

7. M.R. Lemke, T. Wendorff, B. Mieth, K. Buhl, M. Linnemann, Spatiotemporal gait patterns during over ground locomotion in major depression compared with healthy controls, Journal of Psychiatric Research 34(4-5) (2000) 277-283.

8. B.H. Bewernick, A.S. Urbach, A. Broder, S. Kayser, T.E. Schlaepfer, Walking away from depression-motor activity increases ratings of mood and incentive drive in patients with major depression, Psychiatry Research 247 (2017) 68-72.

9. M.R. Lemke, Motor phenomena in depression, Nervenarzt 70(7) (1999) 600-+. 
10. N. Razavi, H. Horn, P. Koschorke, S. Hugli, O. Hofle, T. Muller, W. Strik, S. Walther, Measuring motor activity in major depression: The association between the Hamilton Depression Rating Scale and actigraphy, Psychiatry Research 190(2-3) (2011) 212-216.

11. J. Hoeppner, F. Padberg, G. Domes, A. Zinke, S.C. Herpertz, N. Grossheinrich, U. Herwig, Influence of repetitive transcranial magnetic stimulation on psychomotor symptoms in major depression, European Archives of Psychiatry and Clinical Neuroscience 260(3) (2010) 197-202.

12. H.S. Jorgensen, H. Nakayama, H.O. Raaschou, T.S. Olsen, RECOVERY OF WALKING FUNCTION IN STROKE PATIENTS - THE COPENHAGEN STROKE STUDY, Archives of Physical Medicine and Rehabilitation 76(1) (1995) 27-32.

13. G. Kwakkel, B.J. Kollen, Predicting activities after stroke: what is clinically relevant? International Journal of Stroke 8(1) (2013) 25-32.

14. C. Malsch, T. Liman, S. Wiedmann, B. Siegerink, M.K. Georgakis, S. Tiedt, M. Endres, P.U. Heuschmann, Outcome after stroke attributable to baseline factors-The PROSpective Cohort with Incident Stroke (PROSCIS), PloS one 13(9) (2018).

15. J. Gainey, J. Brecthtel, B. Blum, A. Keels, L. Madeline, E. Lowther, I.T. Nathaniel, Functional Outcome Measures of Recombinant Tissue Plasminogen Activator-Treated Stroke Patients in the Telestroke Technology, Journal of Experimental Neuroscience 12 (2018) 1-11.

16. A. Baccaro, Y.P. Wang, M. Candido, A.B. Conforto, A.R. Brunoni, C.D. Leite, G. Busatto, P.A. Lotufo, I.M. Bensenor, A.C. Goulart, Post-stroke depression and cognitive impairment: Study design and preliminary findings in a Brazilian prospective stroke cohort (EMMA study), Journal of Affective Disorders 245 (2019) 72-81.

17. J.F. Li, Y. Li, P. Li, M.Y. Ye, Early Symptom Measurement of Post-Stroke Depression: Development and validation of a new short version, Journal of Advanced Nursing 75(2) (2019) 482-493.

18. S.S. Wilkins, N. Akhtar, A. Salam, P. Bourke, S. Joseph, M. Santos, A. Shuaib, Acute post stroke depression at a Primary Stroke Center in the Middle East (vol 13, e0208708, 2018), PloS one 14(2) (2019).

19. M.A. Yildirim, K. Ones, Post stroke depression and related factors, Dusunen Adam-Journal of Psychiatry and Neurological Sciences 32(1) (2019) 52-57.

20. W. Cai, C. Mueller, Y.J. Li, W.D. Shen, R. Stewart, Post stroke depression and risk of stroke recurrence and mortality: A systematic review and meta-analysis, Ageing Research Reviews 50 (2019) 102-109.

21. M. Taylor-Rowan, O. Momoh, L. Ayerbe, J.J. Evans, D.J. Stott, T.J. Quinn, Prevalence of pre-stroke depression and its association with post-stroke depression: a systematic review and meta-analysis, Psychological Medicine 49(4) (2019) 685-696.

22. T.I. Nathaniel, T. Cochran, J. Chaves, E. Fulmer, C. Sosa, S. Yi, M. Fredwall, S. Sternberg, D. Blackhurst, A. Nelson, R. Leacock, Co-morbid conditions in use of recombinant tissue plasminogen activator (rt-PA) for the treatment of acute ischaemic stroke, Brain injury 30(10) (2016) 1261-1265.

23. M.J. Colello, L.E. Ivey, J. Gainey, R.V. Faulkner, A. Johnson, L. Brechtel, L. Madeline, T.I. Nathaniel, Pharmacological thrombolysis for acute ischemic stroke treatment: Gender differences in clinical risk factors, Advances in Medical Sciences 63(1) (2018) 100-106.

24. J. Gainey, L. Brechtel, S. Konklin, L. Madeline, E. Lowther, B. Blum, T.I. Nathaniel, In a stroke cohort with incident hypertension; are more women than men likely to be excluded from recombinant tissue-type Plasminogen Activator (rtPA)?, Journal of the neurological sciences 387 (2018) 139-146.

25. L.H. Schwamm, G.C. Fonarow, M.J. Reeves, W. Pan, M.R. Frankel, E.E. Smith, G. Ellrodt, C.P. Cannon, L. Liang, E. Peterson, K.A. LaBresh, Get With the Guidelines-Stroke Is Associated With Sustained Improvement in Care for Patients Hospitalized With Acute Stroke or Transient Ischemic Attack, Circulation 119(1) (2009) 107-U206.

26. S. Zhang, Z. Liu, Y.L. Liu, Y.L. Wang, T. Liu, X.B. Cui, Prevalence of stroke and associated risk factors among middle-aged and older farmers in western China, Environmental Health and Preventive Medicine 22(1) (2017).

27. T.E. Madsen, J.C. Khoury, K.A. Alwell, C.J. Moomaw, B.M. Kissela, F. De Los Rios La Rosa, D. Woo, O. Adeoye, M.L. Flaherty, P. Khatri, S. Ferioli, D. Kleindorfer, Analysis of tissue plasminogen activator eligibility by sex in the Greater Cincinnati/Northern Kentucky Stroke Study, Stroke 46(3) (2015) 717-21.

28. P. Sobolewski, W. Brola, M. Wiszniewska, W. Szczuchniak, M. Fudala, M. Domagalski, M. SledzinskaDzwigal, Intravenous thrombolysis with rt-PA for acute ischemic stroke within $24 \mathrm{~h}$ of a transient ischemic attack, Journal of the neurological sciences 340(1-2) (2014) 44-49. 
29. I.T. Nathaniel, J. Gainey, B. Blum, C. Montgomery, Clinical Risk Factors in Thrombolysis therapy: Telestroke Versus Nontelestroke, Journal of stroke and Cerebrovascualr Disease (2018).

30. L. Akijian, D. Ni Chroinin, E. Callaly, N. Hannon, M. Marnane, A. Merwick, O. Sheehan, D. Hayden, G. Horgan, J. Duggan, L. Kyne, K. O'Rourke, S. Murphy, E. Dolan, D. Williams, P.J. Kelly, Why do transient ischemic attack patients have higher early stroke recurrence risk than those with ischemic stroke? Influence of patient behavior and other risk factors in the North Dublin Population Stroke Study, International Journal of Stroke 12(1) (2017) 96-104.

31. D. Tursunov, Z. Akbarkhodjaeva, Risk factors of developing transient ischemic attack, Journal of the neurological sciences 381 (2017) 1115-1115.

32. E. Demirturk, R.H. Asilar, The effect of depression on adherence to antihypertensive medications in elderly individuals with hypertension, Journal of Vascular Nursing 36(3) (2018) 129-139.

33. N. Hamieh, P. Meneton, E. Wiernik, F. Limosin, M. Zins, M. Goldberg, M. Melchior, C. Lemogne, Depression, treatable cardiovascular risk factors and incident cardiac events in the Gazel cohort, International Journal of Cardiology 284 (2019) 90-95.

34. S.S. Wilkins, N. Akhtar, A. Salam, P. Bourke, S. Joseph, M. Santos, A. Shuaib, Acute post stroke depression at a Primary Stroke Center in the Middle East, PloS one 13(12) (2018).

35. A. Chaturvedi, A. Joshi, P. Chandrika, T. Sharma, M. Castagnaro, C. Alpert, I. Poornima, A. Raina, increased clinical burden of heart failure in patients with depression: insights from the national inpatient sample database, Journal of the American College of Cardiology 73(9) (2019) 915-915.

36. P. Prabhakar, K.S. Allen, V.M. Carter, D.L. Wirth, T.E. Quest, M.O. Ogunniyi, A.A. Lal, Depression screening in a safety-net heart failure clinic: lessons learned, Journal of the American College of Cardiology 73(9) (2019) 859-859.

37. S.A. Everson, R.E. Roberts, D.E. Goldberg, G.A. Kaplan, Depressive symptoms and increased risk of stroke mortality over a 29-year period, Archives of Internal Medicine 158(10) (1998) 1133-1138.

38. M. Antonioli, J. Rybka, L.A. Carvalho, Neuroimmune endocrine effects of antidepressants, Neuropsychiatric Disease and Treatment 8 (2012) 65-83.

39. M. Daskalopoulou, J. George, K. Walters, D.P. Osborn, G.D. Batty, D. Stogiannis, E. Rapsomaniki, M. Pujades-Rodriguez, S. Denaxas, R. Udumyan, M. Kivimaki, H. Hemingway, Depression as a Risk Factor for the Initial Presentation of Twelve Cardiac, Cerebrovascular, and Peripheral Arterial Diseases: Data Linkage Study of 1.9 Million Women and Men, PloS one 11(4) (2016).

40. A.K. Dhar, D.A. Barton, Depression and the Link with Cardiovascular Disease, Frontiers in Psychiatry 7 (2016).

41. S. Bangalore, R. Shah, E. Pappadopulos, C.G. Deshpande, A. Shelbaya, R. Prieto, J. Stephens, R.S. McIntyre, Cardiovascular hazards of insufficient treatment of depression among patients with known cardiovascular disease: a propensity score adjusted analysis, European Heart Journal-Quality of Care and Clinical Outcomes 4(4) (2018) 258-266.

42. R.S. Patel, S. Shrestha, H. Saeed, S. Raveendranathan, E.E. Isidahome, V. Ravat, M.O. Fakorede, V. Patel, Comorbidities and Consequences in Hospitalized Heart Failure Patients with Depression, Cureus 10(8) (2018).

43. K. Yeswanthi, B. Aswani, P. Vijayasanthi, K. Lavanya, B. Prasanth, A REVIEW ON DEPRESSION - POST STROKE COMPLICATION, Indo American Journal of Pharmaceutical Sciences 3(10) (2016) 1203-1209.

44. T.C. Alves, J. Rays, R. Fraguas, M. Wajngarten, R.M.S. Telles, D. Souza, Association between major depressive symptoms in heat failure and impaired regional cerebral blood flow in the medial temporal region: a study using 99tc-HMPAO single photon emission computerized tomography (SPECT). Psychological Medicine 36 (2006) 597-608. 